\title{
Komposisi Gastropoda di Hutan Mangrove Pulau Sepok Keladi Kabupaten Kubu Raya Kalimantan Barat
}

\author{
Habil Algifari ${ }^{1}$, Junardi $^{1}$, Tri Rima Setyawati ${ }^{1}$ \\ ${ }^{1}$ Program Studi Biologi, Fakultas MIPA, Universitas Tanjungpura, Prof.Dr. H. Hadari Nawawi, Pontianak, \\ Email korespondensi: habil07@yahoo.com
}

\begin{abstract}
Gastropods are an invertebrata which has an important role as an indicator quality mangrove forest. The presence of Gastropods in Sepok Keladi mangrove forest was decreasing due the habitat degradation and it impact on the Gastropods community. The purpose of this research is to determine the diversity of Gastropod species in mangrove forest Sepok Keladi Island Kakap River District Kubu Raya Regency. This study uses purposive random sampling method at six different stations with two $5 \times 5 \mathrm{~m}^{2}$ size plots in each station and four replication. The study found four families of Gastropods, i.e. Ellobidae, Littorinidae, Neritidae and Potamidiidae. Epifauna Gastropods found nine species and are five of them are treefauna. The most species foundy Cerethidae obtusa from Potamididae family.
\end{abstract}

Keywords : Cerethidae obtusa, Composition, Gastropods, Mangrove

\section{PENDAHULUAN}

Hutan mangrove di Kalimantan Barat yang mengalami kerusakan mencapai $52 \%$ dari total luas 342.600,01 Ha (BPDAS Kapuas, 2006). Ekosistem mangrove yang sudah mengalami kerusakan di provinsi ini salah satunya ada di Wilayah hutan mangrove Pulau Sepok Keladi.

Pulau Sepok Keladi merupakan salah satu pulau yang terletak di Kecamatan Sungai Kakap Kabupaten Kubu Raya yang telah ditetapkan pemerintah sebagai hutan lindung berdasarkan SK.2762/Menhut-VII/KUH/2014 14/04/2014. Pulau ini memiliki berbagai macam vegetasi yang didominansi oleh vegetasi nipah (Nypa fruticans). Namun saat ini homogenitas tumbuhan nipah di pulau tersebut mulai berkurang akibat aktifitas pengambilan bagian-bagian tumbuhan sehingga mengurangi kerapatan vegetasinya. Hal tersebut akan berpengaruh terhadap komposisi keanekaragaman fauna yang hidup di dalamnya salah satunya adalah Gastropoda.

Gastropoda merupakan salah satu kelas hewan moluska yang hidup di hutan mangrove dengan komposisi, keanekaragaman, dan penyebarannya dapat menurun akibat berkurangnya kerapatan vegetasi. Menurut Budhiman et al, (2001) berkurangnya kerapatan vegetasi akibat faktor manusia lebih berpengaruh terhadap Gastrpoda daripada faktor alami. Tujuan dari penelitian ini yaitu untuk mengetahui komposisi jenis Gastropoda di kawasan mangrove Pulau Sepok Keladi Kecamatan Sungai Kakap Kabupaten Kubu Raya Kalimantan Barat.

\section{BAHAN DAN METODE}

\section{Waktu dan Tempat Penelitian}

Penelitian dilaksanakan pada bulan Juli-Agustus 2017 di kawasan hutan mangrove Pulau Sepok Keladi Kecamatan Sungai Kakap Kabupaten Kubu Raya. Proses identifikasi dilakukan di Laboratorium Zoologi Fakultas Matematika dan Ilmu Pengetahuan Alam Universitas Tanjungpura, Pontianak.

\section{Deskripsi Lokasi}

Wilayah hutan mangrove Pulau Sepok Keladi Kecamatan Sungai Kakap Kabupaten Kubu Raya Kalimantan Barat terletak berseberangan dengan pulau nyamuk di bagian utara, Pulau Sepok Laut di bagian selatan, Laut Natuna di bagian barat dan delta Sungai Kapuas di bagian timur. Pulau Sepok Keladi memiliki hutan mangrove yang didominasi oleh tumbuhan nipah. Selain itu ditemukan juga tumbuhan lain yaitu pohon berus (Brugueira) dan pohon api-api (Avicennia). Pulau ini secara administratif termasuk dalam kecamatan Sungai Kakap Kabupaten Kubu Raya Kalimantan Barat.

\footnotetext{
Alat dan Bahan

Alat-alat yang digunakan adalah, GPS garmin Map 76, Kamera Canon EOS 7D, meteran gulung, oven, refractometer (Atago ATC-S/Mill-E, Japan), sekop kecil, soil tester Rapited, termometer timbangan digital, dan Alat tulis. Bahan-bahan yang digunakan dalam penelitian ini adalah alkohol $70 \%$, almunium foil, aquades, botol sampel, kantong plastik, kertas label dan kertas $\mathrm{pH}$ Universal.
} 


\section{Metode Penelitian}

Pengambilan sampel dilakukan di setiap stasiun dengan menetapkan dua plot berukuran $5 \times 5 \mathrm{~m}^{2}$ yang diletakkan secara acak (random sampling). Peta lokasi penelitian dan deskripsi lokasi masingmasing stasiun pengambilan sampel disajikan pada
Gambar1. dan Tabel 1. Pengambilan sampel dilakukan sebanyak empat kali pengulangan berdasarkan kalender bulan (lunar calendar) yaitu fullmoon, first quarter, newmoon, dan third quarter.

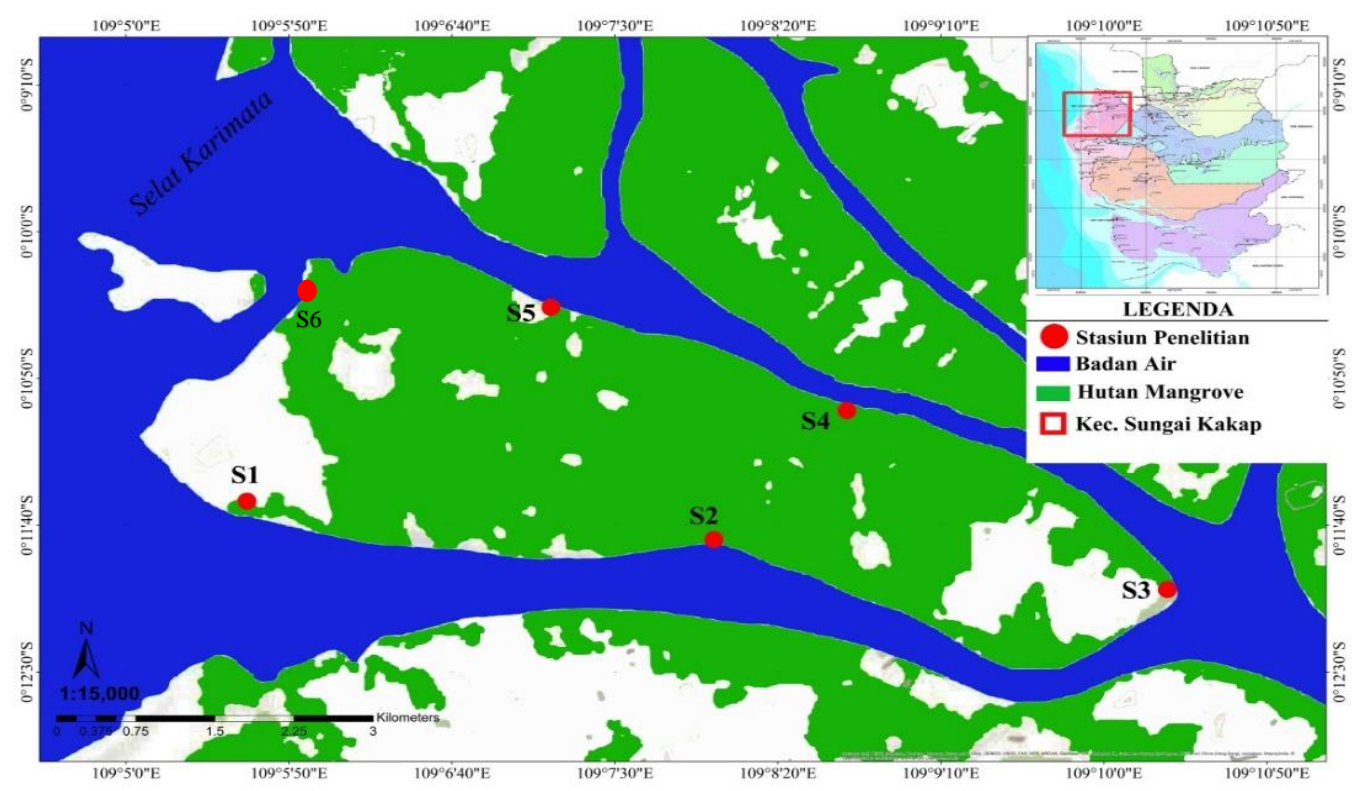

Gambar 1. Peta Stasiun Penelitian di Hutan Mangrove Pulau Sepok Keladi

Tabel 1. Lokasi Habitat Stasiun Penelitian

\begin{tabular}{|c|c|c|}
\hline Stasiun & Habitat & Titik Koordinat \\
\hline $\mathrm{I}$ & $\begin{array}{l}\text { Tutupan vegetasi hanpir tidak ada, struktur tanah padat, } \\
\text { didominasi semak belukar }\end{array}$ & $\begin{array}{r}0^{\circ} 11^{\prime} 31.79^{\prime \prime} \mathrm{LS} \\
109^{\circ} 5 \text { '37.13" BT }\end{array}$ \\
\hline II & $\begin{array}{l}\text { Vegetasi mangrove heterogen, didominasi pohon nipah dan } \\
\text { sebagian pohon berus, tutupan pohon rapat }\end{array}$ & $\begin{array}{r}0^{\circ} 11^{\prime} 44.83^{\prime \prime} \mathrm{LS} \\
109^{\circ} 88^{\prime} 0.39^{\prime \prime} \mathrm{BT}\end{array}$ \\
\hline III & $\begin{array}{l}\text { Berada di dekat delta Sungai Kapuas, vegetasi mangrove } \\
\text { didominasi pohon nipah }\end{array}$ & $\begin{array}{r}0^{\circ} 12^{\prime} 1.83^{\prime \prime} \mathrm{LS} \\
109^{\circ} 10^{\prime} 19.52^{\prime \prime} \mathrm{BT}\end{array}$ \\
\hline IV & $\begin{array}{l}\text { Vegetasi heterogen didominasi pohon nipah, sebagian kecil } \\
\text { terdapat tumbuhan api-api, tutupan rapat }\end{array}$ & $\begin{array}{r}0^{\circ} 11^{\prime} 0.90^{\prime \prime} \mathrm{LS} \\
109^{\circ} 8141.19^{\prime \prime} \mathrm{BT}\end{array}$ \\
\hline V & $\begin{array}{l}\text { Pintu masuk Pulau Sepok Keladi, vegetasi mangrove homogen } \\
\text { didominasi pohon nipah }\end{array}$ & $\begin{array}{r}0^{\circ} 10^{\prime} 23.83^{\prime \prime} \mathrm{LS} \\
109^{\circ} 7^{\prime} 11.68^{\prime \prime} \mathrm{BT}\end{array}$ \\
\hline V1 & $\begin{array}{l}\text { Vegetasi heterogen didominasi pohon nipah, sebagian kecil } \\
\text { terdapat tumbuhan api-api, berbatasan dengan tepi laut }\end{array}$ & $\begin{array}{r}0^{\circ} 10^{\prime} 25.54 " \mathrm{LS} \\
109^{\circ} 5{ }^{\prime} 51.47^{\prime \prime} \mathrm{BT}\end{array}$ \\
\hline
\end{tabular}

Keterangan: LS (Lintang Selatan) dan BT (Bujur Timur)

Gastropoda yang diambil meliputi kelompok epifauna dan treefauna yang diambil langsung menggunakan tangan (hand sorting). Sampel yang didapatkan dari lapangan selanjutnya dipisah dan dihitung jumlah individunya. Sampel yang didapat dipreparasi dengan cara menyuntikkan formalin $4 \%$ pada bagian ventral, kemudian tubuhnya ditutupi dengan tisu yang juga telah dibasahi dengan formalin 4\%. Sampel kemudian dicuci dengan air mengalir dan direndam dalam alkohol 70\%. Sampel kemudian diidentifikasi berdasarkan Kusnadi (2008), Frest (1999) dan Dillon (2013). Proses identifikasi dilakukan dengan memperhatikan karakteristik morfologi cangkang dan operkulum. 


\section{HASIL DAN PEMBAHASAN}

\section{Hasil}

Komposisi Spesies

Gastropoda yang ditemukan di kawasan hutan mangrove Pulau Sepok Keladi Kecamatan Sungai Kakap Kabupaten Kubu Raya sebanyak 9 spesies yaitu Auriculastra saccata, Cerithidae obtusa, Ellobium aurismidae, Littorina sp., Neritida violaceae, Ophicardelus costellaris, Pythia fimbriata, Pythia pantherina, dan Tereblaria sulcata. Spesies-spesies tersebut termasuk dalam 4 famili, yaitu Ellobidae, Littorinidae, Neritidae dan Potamidiidae (Gambar 2).
Spesies dengan jumlah individu terbanyak adalah spesies Cerethidae obtusa dengan jumlah individu sebanyak 1437 ekor. Jumlah individu terbanyak kedua adalah spesies Neritina violaceae dengan jumlah sebanyak 359 ekor. Jumlah individu yang paling sedikit adalah Ellobium aurismidae dengan jumlah 28 ekor.

Gastropoda yang ditemukan berdasarkan cara hidup terbagi menjadi dua yaitu epifauna dan treefauna yang masing-masing berturut-turut ditemukan sebanyak 9 jenis dan 5 famili (Tabel 2).

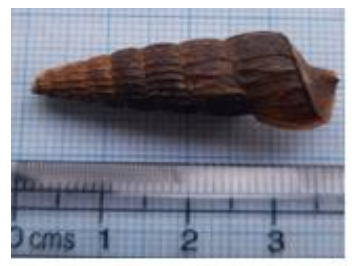

(a)

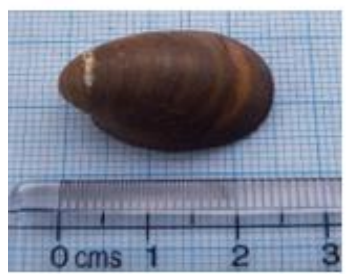

(d)

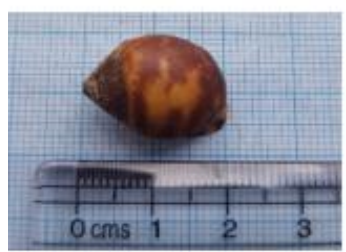

(g)

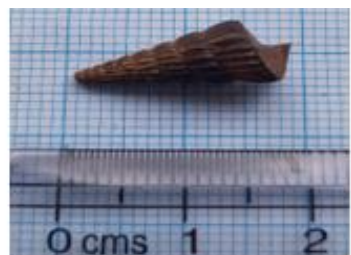

(b)

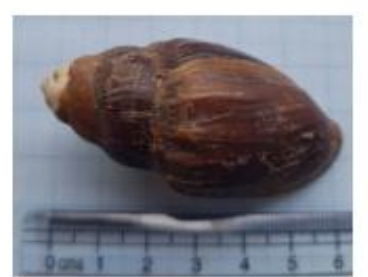

m(e)

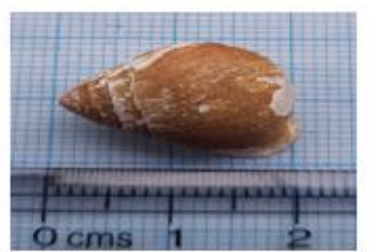

(h)

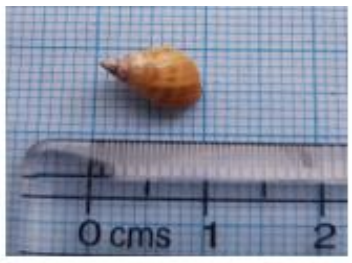

(c)

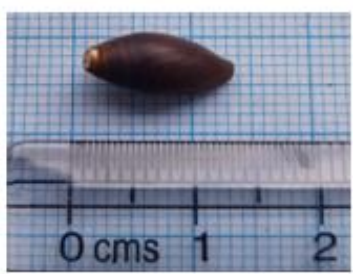

(f)

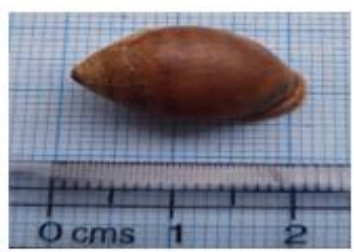

(i)

Gambar 2. Spesies-spesies Gastropoda yang ditemukan di hutan mangrove Pulau Sepok Keladi; (a) Cerethidae obtusa, (b) Tereblalia sultaca, (c) Littorina sp., (d) Neritina violaceae, (e) Ellobium aurismidae, (f) Auriculastra saccata (g) Pythia pantherina, (h) Pythia tigronus, dan (i) Ophicardelus costellaris.

Tabel 2. Spesies Gastropoda yang Ditemukan Berdasarkan Sifat Hidup

\begin{tabular}{llcc}
\hline & \multicolumn{1}{c}{ Samili } & Epesies & Treefauna \\
\hline Ellobiidae & Auriculastra saccata & + & - \\
& Elobium aurismidae & + & + \\
& Ophicardelus costellaris & + & + \\
& Pythia fimbriata & + & - \\
Littorinidae & Pythia pantherina & + & + \\
Neritidae & Littorina sp. & + & + \\
Potamididae & Neritida violaceae & + & + \\
& Cerethidae obtusa & + & + \\
\hline & Tereblalia sulcata & $\mathbf{9}$ & $\mathbf{5}$ \\
\hline
\end{tabular}

Keterangan:(+):Ditemukan, (-): Tidak ditemukan 


\section{Pembahasan}

Keberadaan Gastropoda dipengaruhi oleh pasangsurut, perubahan suhu, salinitas dan ketersediaan bahan organik dengan substrat berlumpur yang disukai Gastropoda. Menurut Merly dan Elviana (2017) keberadaan Gastropoda pada suatu perairan dipengaruhi oleh tingginya kadar organik yang terdapat pada substrat berlumpur.

Pengambilan sampel dilakukan berdasarkan tiga kelompok mikrohabitat yaitu epifauna, treefauna dan infauna. Sampel yang paling banyak ditemukan dari kelompok epifauna. Hal ini dikarenakan Gastropoda sangat menyukai substrat berlumpur yang memiliki kandungan organik yang cukup tinggi. Menurut Tuheteru et al. (2014), Gastropoda yang berada di atas permukaan tanah menyukai permukaan lumpur dan ketersediaan bahan organik yang tinggi. Faktor lain yang menyebabkan kelompok epifauna banyak ditemukan karena vegetasi mangrove yang cukup rapat. Menurut Rangan (2010), Gastropoda banyak ditemukan di vegetasi mangrove yang rapat untuk menghindari kekeringan.

Famili dengan jumlah individu terbanyak ditemukan adalah Potamidiidae. Lokasi penelitian yang merupakan tempat terjadinya pasang-surut menyebabkan famili Potamidiidae sangat toleran terhadap kondisi tersebut. Menurut Rangan (2010),

Famili Potamididae memiliki toleransi tinggi terhadap perubahan lingkungan akibat faktor fisik di luar mangrove yaitu pasang-surut air laut dan salinitas yang tinggi sehingga organisme tersebut dapat bertahan hidup dan berkembang di hutan mangrove. Kelompok epifauna yang memiliki kelimpahan tertinggi yang ditemukan adalah spesies Cerethidae obtusa dan Tereblalia sulcata dari famili Potamidiidae dan Neritina violaceae dari famili Neritidae. Spesies- spesies tersebut memiliki mobilitas lebih tinggi dibandingkan dengan spesies lainnya untuk bergerak sehingga memiliki kisaran toleransi yang cukup luas terhadap faktor lingkungan (Berry, 1971).

Kelompok treefauna ditemukan lebih sedikit dibandingkan dengan epifauna, yaitu berjumlah lima spesies. Spesies-spesies yang ditemukan pada kelompok treefauna adalah Cerethidae obtua, Tereblalia sulcata, Ophicardellus costellaris, Littorina sp., dan Neritina violaceae. Kelompok dari lima spesies tersebut termasuk dalam kelompok treefauna, sementara spesies-spesies yang hanya infauna adalah Auriculastra saccata, Ellobium aurismidae, Pythia pantherine, dan Pythia fimbriata. Spesies-spesies yang termasuk dalam dua kelompok ini memiliki kemampuan bergerak bebas, sehingga saat air pasang akan berpindah ke atas untuk menghindari tingginya air ketika sedang pasang (Tuheteru et al., 2014).

Spesies Cerethidae obtusa dan Tereblalia sulcata dari famili Potamididae banyak ditemukan menempel di atas pohon dan sebagian di permukaan tanah. Hal ini disebabkan karena famili Potamididae memiliki kisaran toleransi yang luas terhadap pasang-surut laut. Berdasarkan tingkat toleransi terhadap lingkungan, Gastropoda memiliki dua tingkatan yaitu tingkat toleransi tinggi dan rendah. Spesies dari Cerethidae obtusa memiliki toleransi tinggi, sedangkan Tereblalia sulcata memiliki toleransi rendah. Spesies Cerethidae obtusa beradaptasi dengan cara naik ke atas pohon dan menguburkan sebagian tubuhnya ke dalam tanah sedangkan Tereblalia sulcata cenderung memanjat akar dan pohon untuk menghindari air pasang (Arbi, 2014).

Spesies Neritina violaceae dari anggota famili Neritidae banyak ditemukan di pohon karena memiliki ukuran cangkang yang relatif kecil untuk berpindah ke pohon untuk perlindungan diri dari serangan predator dan menghindari dari pasangsurut laut. Menurut Darmi (2016), famili Neritidae ditemukan menempel pada batang mangrove yang merupakan bagian dari perlindungan diri untuk menghindari serangan predator dan terbawa ombak saat air laut pasang.

Spesies Littorina sp. termasuk dalam kelompok treefauna dapat ditemukan di pohon karena memiliki ciri-ciri yang paling menonjol yaitu memiliki cangkang yang tipis dan mempunyai alat penempel berupa perut dengan modifikasi sel yang dapat mengeluarkan cairan perekat yang kuat (Karwati, 2004). Gastropoda dengan spesies yang paling dominan adalah Cerithidae obtusa dari kelas Potamidiidae. Dari pengambilan sampel bedasarkan dua sifat hidup, epifauna paling banyak ditemukan dengan jumlah sebanyak 9 spesies, sedangkan treefauna 5 spesies.

\section{DAFTAR PUSTAKA}

Arbi, YU, 2014, Taksonomi dan Filogeni Keong Famili Potamididae di Indonesia Berdasarkan Karakter Morfologi, Tesis, Program Studi Ilmu Kelautan, Institut Pertanian Bogor, Bogor 
Balai Pengelolaan Daerah Aliran Sungai Kapuas, 2006, Identifikasi dan Inventarisasi Mangrove di Wilayah Kerja Balai Pengelolaan Daerah Aliran Sungai Kapuas, Pontianak, Kalimantan Barat

Berry, AJ, 1971, The Natural History of West Malaysian Mangroves Fauna, Malay Natio Journal, vol. 25, hal. 135-162

Budhiman S, R, Dewanti, C, Kusmana \& N, Puspaningsih, 2001, Kerusakan Hutan Mangrove di Pulau Lombok Menggunakan Data LandsatTM dan Sistem Informasi Geografis (SIG), Warta LAPAN, vol. 3, no. 4, hal. 201-202

Darmi, 2016, Keanekaragaman Gastropoda di Kawasan Hutan Mangrove Muara Sungai Kuala Baru Kecamatan Jawai Kabupaten Sambas, Skripsi, Fakultas Matematika dan Ilmu Pengetahuan Alam, Universitas Tanjungpura, Pontianak

Dillon, RT, 2013, The Freshwater Gastropods of North America, Diakses Tanggal 09 Februari, http://www.fwgna.org

Frest, JT \& Johannes, JE, 1999, Field Guide to Survey and Manage Freshwater Mollusk Species, USFWS Regional Ecosystem Office, Survey, and Manage Team, Oregon

Karwati, N, 2002, Struktur Gastropoda dan Bivalvia pada Ekosistem Mangrove dan Padang Lamun di Gugus Pulau Pari, Kepulauan Seribu, Skripsi, Program Manajemen Sumberdaya Perairan Fakultas Perikanan dan Ilmu Kelautan, IPB, Bogor

Kusnadi, A, Hernawan, UE \& Triandiza, T, 2008, Moluska Padang Lamun Kepulauan Kei Kecil, Lembaga Ilmu Pengetahuan Indonesia Press, Jakarta

Merly, LS \& Elviana ,S, 2017, 'Korelasi Sebaran Gastropoda dan Bahan Organik Dasar pada Ekosistem Mangrove di Perairan Pantai Payum, Merauke', Dinamika Maritim, vol. 6, no. 1, hal. $18-22$

Rangan, JK, 2010, Inventarisasi Gastropoda di Lantai Hutan Mangrove Deas Rap-rap Kabupaten Minahasa Selatan Sulawesi Utara, Skripsi, Program Studi Manajemen Sumberdaya Perairan Fakultas Perikanan dan Ilmu Kelautan, UNSRAT, Manado

Tuheteru, M, Notosoedarmo, S, Martosupono, M, 2014, Distribusi Gastropoda di Ekosistem Mangrove, Tesis, Program Studi Magister Biologi, Universitas Kristen Satya Wacana, Salatiga 